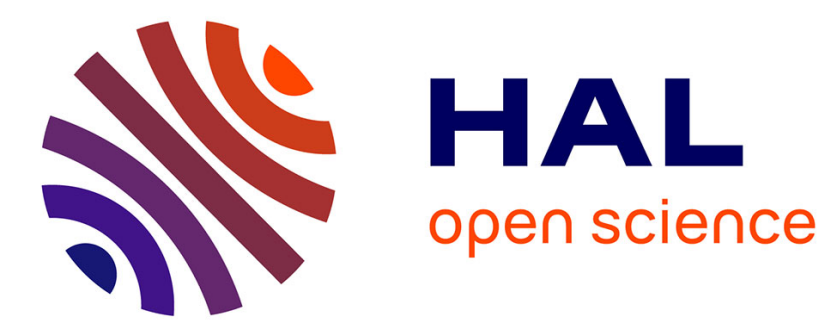

\title{
Quartz resonators thermal modelization using located constants networks
}

\author{
S. Galliou, J.P. Valentin
}

\section{To cite this version:}

S. Galliou, J.P. Valentin. Quartz resonators thermal modelization using located constants networks. Revue de Physique Appliquée, 1987, 22 (4), pp.235-240. 10.1051/rphysap:01987002204023500 . jpa00245536

\section{HAL Id: jpa-00245536 https://hal.science/jpa-00245536}

Submitted on 1 Jan 1987

HAL is a multi-disciplinary open access archive for the deposit and dissemination of scientific research documents, whether they are published or not. The documents may come from teaching and research institutions in France or abroad, or from public or private research centers.
L'archive ouverte pluridisciplinaire HAL, est destinée au dépôt et à la diffusion de documents scientifiques de niveau recherche, publiés ou non, émanant des établissements d'enseignement et de recherche français ou étrangers, des laboratoires publics ou privés. 
Classification

Physics Abstracts

$06.30 \mathrm{~K}-05.70$

\title{
Quartz resonators thermal modelization using located constants networks
}

\author{
S. Galliou and J. P. Valentin \\ Laboratoire de Chronométrie, Electronique et Piézoélectricité, La Bouloie, Route de Gray, \\ 25030 Besançon Cedex, France
}

(Reçu le 17 septembre 1986, accepté le 6 janvier 1987)

\begin{abstract}
Résumé. - Un rappel succinct des résultats récents sur la modélisation thermique des résonateurs à quartz est d'abord présenté ; ensuite, la méthode consistant à établir un réseau à constantes localisées à base de résistances et condensateurs est appliquée à une nouvelle structure symétrique de résonateur à quartz. Le modèle construit est testé par comparaison des courbes fréquence-température expérimentales et celles obtenues par le calcul. Le diagramme de Bode de la fonction de transfert thermique est obtenu par analogie électrique. Il apparaît que la nouvelle structure symétrique est particulièrement insensible aux fluctuations rapides de température et qu'une enceinte rudimentaire suffit. De plus, une adaptation de la constante de temps de la structure aboutit à un régime «critique » qui permet d'atteindre rapidement la fréquence finale du résonateur dans le cas d'un chauffage rapide.
\end{abstract}

\begin{abstract}
A short recall on recent results about the thermal modelization of quartz resonators is first presented; next, the method consisting on establishing a located constants network with resistors and capacitors is applyed to the case of a new symmetrical structure of quartz resonator. The designed model is tested by comparison of the experimental frequency versus temperature curves with the calculated ones. By analogy with electrical area, the Bode diagram of the thermal transfer function is obtained. It is pointed out that the new symmetrical structure is particularly insensitive to fast thermal disturbances and may be used with rough ovens. Moreover, with a matched time constant of the structure, a «critical» state appears which permits to rise very quickly the final frequency of the resonator for fast warm up.
\end{abstract}

\section{Introduction.}

Precise quartz resonators are thermostated by an oven. The controlled temperature is the temperature of the enclosure in which the vibrating crystal is maintained with the help of mechanical holders. The goal of a thermal modelization is to know the temperature evolution of the central spot of vibration when the enclosure temperature changes, and to deduce the subsequent frequency shift of the resonator.

In this matter, a first method is to write the diffusion equation of the thermal flux and to solve it using the boundary conditions. The principal difficulty is the knowledge of realistic boundary conditions. Basically this method is pertinent for thermal studies inside the piezoelectric crystal plate. Some recent results in this domain will be resumed at the beginning of the paper.

If the mechanical structure which maintains the crystal inside the enclosure is no more sophisticated, then the analytical method stands realistic. The diffusion equation of the thermal flux is written for each mechanical structure element and at each boundary the continuity is introduced by the energy conservation equation. It is then necessary to introduce either an exchange coefficient or a contact thermal resistor.

A second method is the numerical solvation. This appears appropriated when the mechanical structure is more sophisticated. But quickly a very performant computer must be used with finite elements method or similar methods.

Both methods can become very sophisticated, even no realistic because of calculation hypothesis which are not enough justified.

A third method, used in this work, consists on establishing a located constants network with resistors and capacitors which point out the thermal resistances and capacitances of the various elements. More sophisticated is the structure, more pertinent 
is this method. It was soon fructically used in the electrodeless resonator case [1].

Of course such a method cannot give the temperature distribution inside the crystal plate. Its advantage is to be particularly practical when the time directly interferes in the problem being to solve. So, it is the case of studies of frequency dynamical evolution of resonators submitted to a time dependent temperature law. And so for the starting problems and particularly the fast warm-up problem.

In this paper, a specific quartz resonator is analysed. Though reported to this particular case, the used step keeps general characteristics.

\section{Recent results.}

Recently, an improved thermal model of bulk acoustic wave quartz resonators, different from the « infinite plate » model, was proposed [2]. This model takes into account the actual boundary conditions and energy trapping [3]. Inside the resonator, three parts are distinguished: an internal source part, a transfer part, and an exchange part. Various cases of boundary conditions are examined, specially the case where the resonator is mounted by the help of two opposite holders. Then, in the internal source part, the isotherms equation for polar coordinates $\theta$, $r$, is given by

$$
\begin{aligned}
& T(r, \theta)=T_{0}\left\{1-\frac{r^{2}}{R^{2}} \cos ^{2} \theta+\right. \\
& \left.+\frac{r^{2}}{R^{2}}\left(1-\frac{\alpha R^{2}}{T_{0} p^{2}}\right) \sin ^{2} \theta\right\}
\end{aligned}
$$

where the parameters $T_{0}, R, \alpha$ and $p$ are explicited in the reference [2]. The isotherms are conics or lines and it can be seen that the isotherms are always equilateral hyperbolas inside the transfer part and inside the exchange part.

This thermal model leads to a temperature gradient distribution which is in the main plane of the crystal, and therefore which does not exhibit any functional dependence (at least at the first order) along the plate thickness. Very recently, the corresponding in-plane thermal stresses were calculated [4]. The corresponding bias of the elastic continuum is coupled to the high frequency wave by the nonlinear effects. The result is a perturbation of the resonant frequency of the quartz resonator which could be calculated by using a perturbation method proposed by Tiersten [5]. All numerical results are in good agreement with experiments, establishing finally the validity of the new thermal model.

From this modelling, an electrical analogical network of a quartz resonator crystal plate was proposed [6]. Figure 1 shows this network. The crystal is represented by a third order system driven by two

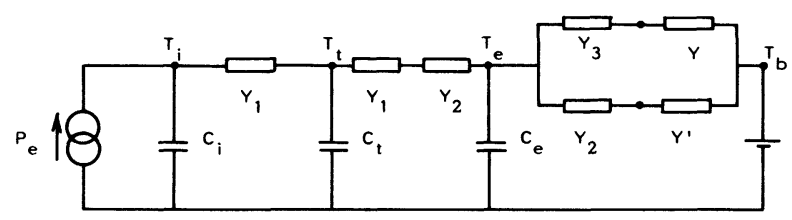

Fig. 1. - Located constants network of a quartz resonator crystal plate.

electrical sources: an intensity source $P_{\mathrm{e}}$ which figures the internal heat source due to the energy dissipation by the internal friction and a voltage source $T_{\mathrm{b}}$ which representes the external temperature (enclosure temperature). All expressions of capacitors and resistors are given in the reference [6]. Typically $\mathrm{Y}_{1}, \mathrm{Y}_{2}, \mathrm{Y}_{3}, \mathrm{C}_{\mathrm{i}}$ and $\mathrm{C}_{\mathrm{e}}$ are representative of the crystal plate, where as $Y$ and $Y^{\prime}$ qualify the thermal exchanges from the crystal to the enclosure. In this matter, it must be pointed out the radiative exchange can occur the principal exchange [6].

In the case of the specific quartz resonator analysed in this paper, only the resistors $\mathrm{Y}$ and $\mathrm{Y}^{\prime}$ will be considered. This fact will be explained later.

\section{B.V.A. resonator.}

The specific quartz resonator which is studied here, is an electrodeless resonator with quartz bridges, like the B.V.A. resonator [7]. We shall give a short presentation of advantages of B.V.A. resonator.

1) It is an «electrodeless design »: all problems that relate to electrode deposition, such as damping, stresses, contamination are removed.

2) The crystal mounting is made of quartz : small bridges connect the vibrating part of the crystal to the dormant part, giving negligible stresses in the mounting points.

Very roughly speaking, the B.V.A. design is capable of an order of magnitude improvement in short-term stability, long-term drift, and acceleration sensitivity over conventional designs [8].

The first thermal analysis of B.V.A. resonators was made in 1982 [9]. Using largely the electrical analogy, this study authorized the establishment of an actual located constants network for B.V.A. resonators. The frequency overshoot in quartz crystal B.V.A. oscillators during the warm-up time has been correctly explained with this modelling network [1].

The analysis developed here is referred to a new model of electrodeless resonator, basically B.V.A. resonator with various differences, called symmetrical structure B.V.A. resonator.

\section{Symmetrical structure B.V.A. resonator.}

The symmetrical structure has been performed essentially in order to reduce the acceleration sensitivi- 
ty of the B.V.A. resonators [10]. The symmetry effect is well known [11] and imposes particularly a symmetrical mounting showing a plane of symmetry parallel to the main plane of the crystal resonator and located at its middle point. That is the case of the new structure (Fig. 2).

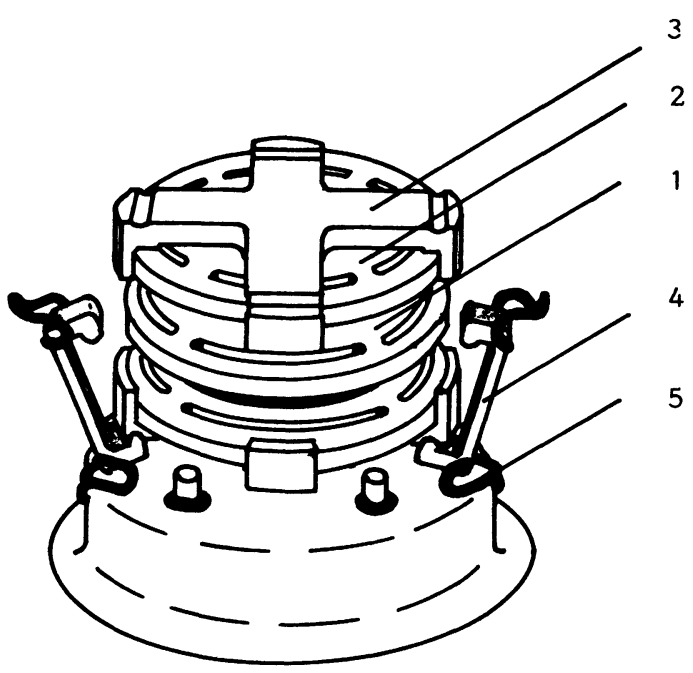

Fig. 2. - Symmetrical structure B.V.A. resonator 1 - Crystal resonator, 2-Quartz capacitor, 3 - Quartz half-shell, 4 - Nippers, 5 - Shape-spring.

Metallic nippers àre used to maintain the capacitor and crystal resonator tighted together. To avoid thermal hysteresis two quartz halfshell are set between capacitor and nippers.

At last the mounting is isolated from external pressure variations by shape-springs which are solded to the nippers.

From previous studied problems - acceleration sensitivity, thermal hysteresis, external pressure variations - the present structure has been performed. Now, keeping into account the new imperative requirements, it is necessary to examine the thermal behaviour of this symmetrical structüre.

\section{Thermal analysis.}

The thermal modelling of the B.V.A. resonator requires an analysis of the exchanges from the enclosure to the crystal across the mechanical structure.

In a first step, the radiation between the various surfaces of the components must be taken into account. On the other hand the conduction, radiation and convection by the residual gas in the enclosure can be omitted.

The wires connecting the electrodes to the electrical pins being very thin, the input thermal flow across these ones is negligible : all the input flow goes through the enclosure. It is divided in eight flows across the springs supposed to be equal because of the symmetry of the mounting structure.

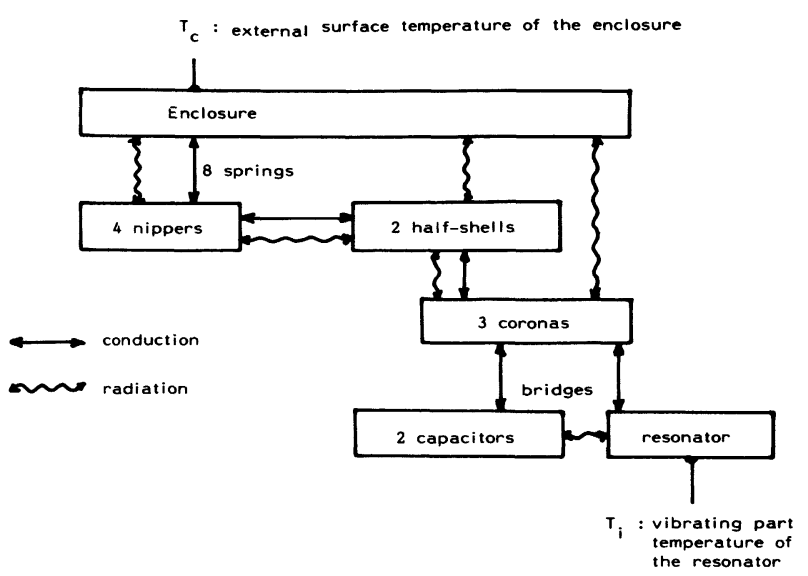

Fig. 3. - Thermal exchanges in a symmetrical structure B.V.A. resonator.

Figure 3 shows all the elements and thermal relations used in the analysis.

5.1 RAdiation. - At $350 \mathrm{~K}$, the maximum of emission is about $8 \mu \mathrm{m}$, so, both the quartz and other materials of the structure are opaque. Moreover, distances between surfaces being small, we can consider the exchanges only exist between parallel opposite surfaces.

In the case of grey bodies, the heat transfer between two surfaces at temperature $T_{1}$ and $T_{2}$ may be written $Q=k\left(T_{1}-T_{2}\right)$, with $k=\mu \sigma F T_{1}^{3}, \mu$ being an angle factor, $F$ a temperature factor $\left(F=\left(1+\frac{T_{2}}{T_{1}}\right)\left(1+\frac{T_{2}^{2}}{T_{1}^{2}}\right)\right)$ and $\sigma$ a coefficient of mutual radiation. $\sigma$ is a function of the roughness and the nature of both considered surfaces [12].

Table I provides average values of exchanges by radiation.

Table I. - Average resistors of radiation exchanges.

\begin{tabular}{|l|r|}
\hline \multicolumn{1}{|c|}{ Exchanges between } & \multicolumn{1}{|c|}{$\begin{array}{c}\text { Radiation } \\
\text { resistors }\end{array}$} \\
\hline 2 capacitors - crystal & $1250^{\circ} \mathrm{C} / \mathrm{W}$ \\
2 capacitors - 2 half-shells & $715^{\circ} \mathrm{C} / \mathrm{W}$ \\
2 half-shells - enclosure & $2500^{\circ} \mathrm{C} / \mathrm{W}$ \\
Coronas - enclosure & $1670^{\circ} \mathrm{C} / \mathrm{W}$ \\
\hline
\end{tabular}

5.2 Solid CONDUCTION. - From one spring, the heat flow is assumed to ramify as shown in figure 4. This choice impose the definition of particular volumes as the ones represented in dotted lines in figure 4. By the means of such a cut up, the contact influences are taken into account; as a matter of fact, the analysis of the contact pressure and surface 


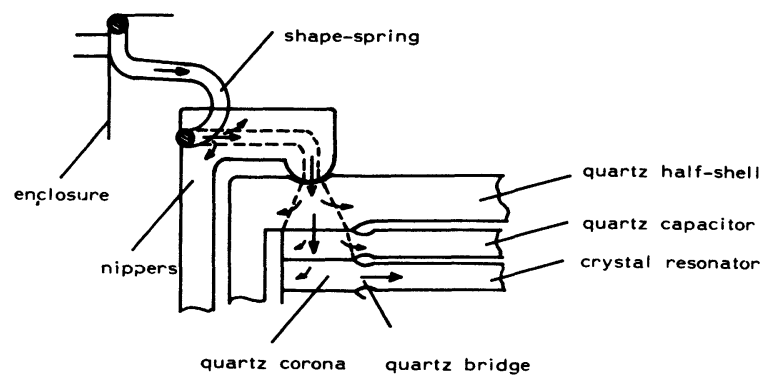

Fig. 4. - Solid conduction.

roughness permits to take as zero the contact resistors [13], the vacuum being better than $10^{-4}$ mbar. The heat transfer at the contact will only depend upon the contact surfaces.

The numerical estimations of the resistors and capacitors can be made for each element of the structure by knowing the direction of the heat flow across well-defined surfaces. In the quartz elements this direction determines more particularly the value of the conductivity.

Using the symmetry of the structure, the foregoing considerations lead to the design of the network shown in figure 5 with the estimated values of the table II. The resistors of the exchanges by radiation, inserted in this analogical network, will not change its behavior. Also, it is justified to consider this model as right by omitting the resistors of radiation exchanges ; it may be pointed out that this model cannot be simplified, all the values being in the same order.

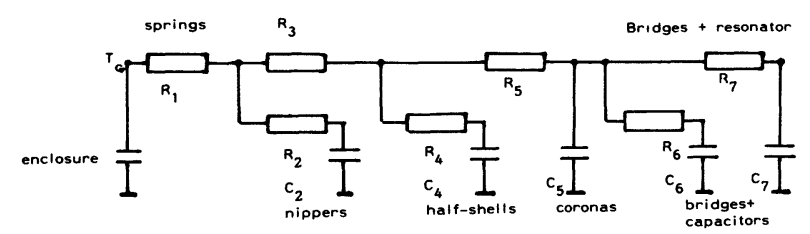

Fig. 5. - Analogical network of the thermal exchanges.

Table II. - Estimated values of the analogical network elements.

\begin{tabular}{|l|l|l|}
\hline Springs & $R_{1}=300^{\circ} \mathrm{C} / \mathrm{W}$ & \\
\hline Nippers & $\begin{array}{l}R_{2}=10^{\circ} \mathrm{C} / \mathrm{W} \\
R_{3}=30^{\circ} \mathrm{C} / \mathrm{W}\end{array}$ & $C_{2}=0,45 \mathrm{~J} /{ }^{\circ} \mathrm{C}$ \\
\hline Half-shells & $R_{4}=11^{\circ} \mathrm{C} / \mathrm{W}$ & $C_{4}=0,7 \mathrm{~J} /{ }^{\circ} \mathrm{C}$ \\
\hline Coronas & $R_{5}=37^{\circ} \mathrm{C} / \mathrm{W}$ & $C_{5}=0,25 \mathrm{~J} /{ }^{\circ} \mathrm{C}$ \\
\hline $\begin{array}{l}\text { Bridges } \\
+ \text { Capacitors }\end{array}$ & $R_{6}=33^{\circ} \mathrm{C} / \mathrm{W}$ & $C_{6}=0,3 \mathrm{~J} /{ }^{\circ} \mathrm{C}$ \\
\hline $\begin{array}{c}\text { Bridges } \\
+ \text { Resonator }\end{array}$ & $R_{7}=34^{\circ} \mathrm{C} / \mathrm{W}$ & $C_{7}=0,16 \mathrm{~J} /{ }^{\circ} \mathrm{C}$ \\
\hline
\end{tabular}

Furthermore, the mechanical structure corresponds to a more complex system than the ordinary elements $Y$ and $Y^{\prime}$ mentioned forward (Paragraph 2), whereas the active part is identified to a first order system, which is satisfying in the present case, with respect to the mounting complexity.

5.3 TEST ON THE MODEL. - In order to test the validity of the model, theorical results have been compared with experimental ones in the case of ramp functions of temperature applied to the enclosure.

The experimental part if shown up figure 6 ; the resonator is subjected to linear temperature runs in a controlled oven, and is looked at a null-phase.

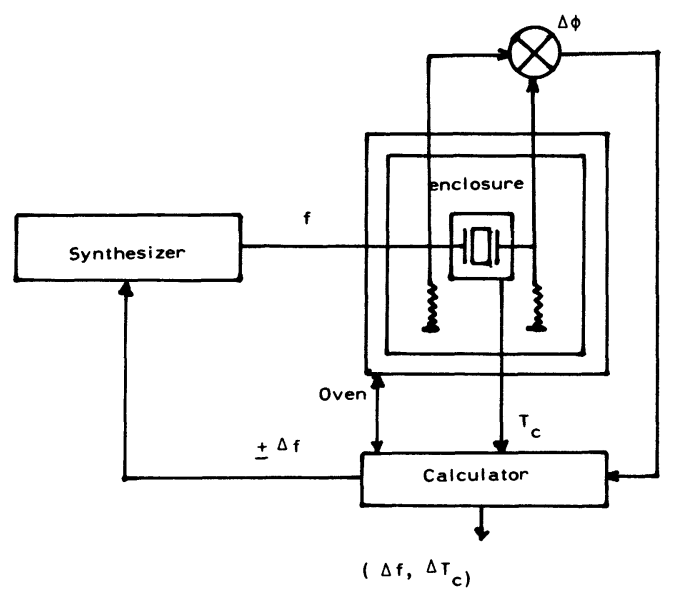

Fig. 6. - Mounting of measurements.

Here, the frequency is the sensor of the active part temperature $T_{\mathrm{i}}$. In the case of a quasi-static run, the crystal temperature, $T_{\mathrm{i}}$, may be taken as equal to the enclosure temperature $T_{\mathrm{c}}$; thus, the frequency-temperature function is determined: $\Delta f=a_{0} \Delta T_{\mathrm{i}}+$ $b_{0} \Delta T_{\mathrm{i}}^{2}+c_{0} \Delta T_{\mathrm{i}}^{3}$.

We can add to this classical cubic a dynamic parameter $\tilde{a}[14]$ :

$$
\Delta f=\left(a_{0}+\tilde{a} \frac{\mathrm{d} T_{\mathrm{i}}}{\mathrm{d} t}\right) \Delta T_{\mathrm{i}}+b_{0} \Delta T_{\mathrm{i}}^{2}+c_{0} \Delta T_{\mathrm{i}}^{3}
$$

The model permits to have $\Delta T_{\mathrm{i}}(t)$ versus $\Delta T_{\mathrm{c}}(t)$ and the forward function to touch $\Delta f$.

The comparison of the experimental frequency excursions with the calculated ones leads to adjust the elements of the model, as shown figure 7 . The final values are equal to the estimated values for the resistor and multiplied by a coefficient 0.8 for the capacitors except for $C_{6}$ and $C_{7}$ assumed to be well defined.

Figures 8a-b-c show the results of the comparison (for AT-cut) when the enclosure temperature increases from $23^{\circ} \mathrm{C}$ to $95^{\circ}$ in 12 hours (quasi-static), 3 hours and 1 hour. 


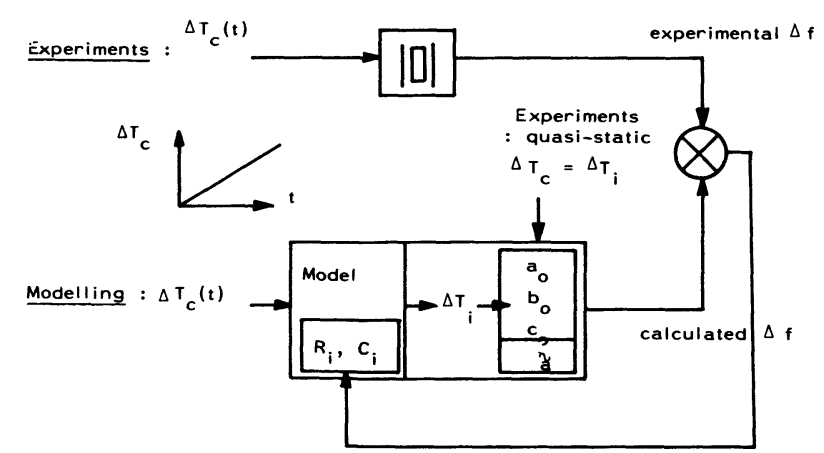

Fig. 7. - Adjustement of the model elements.
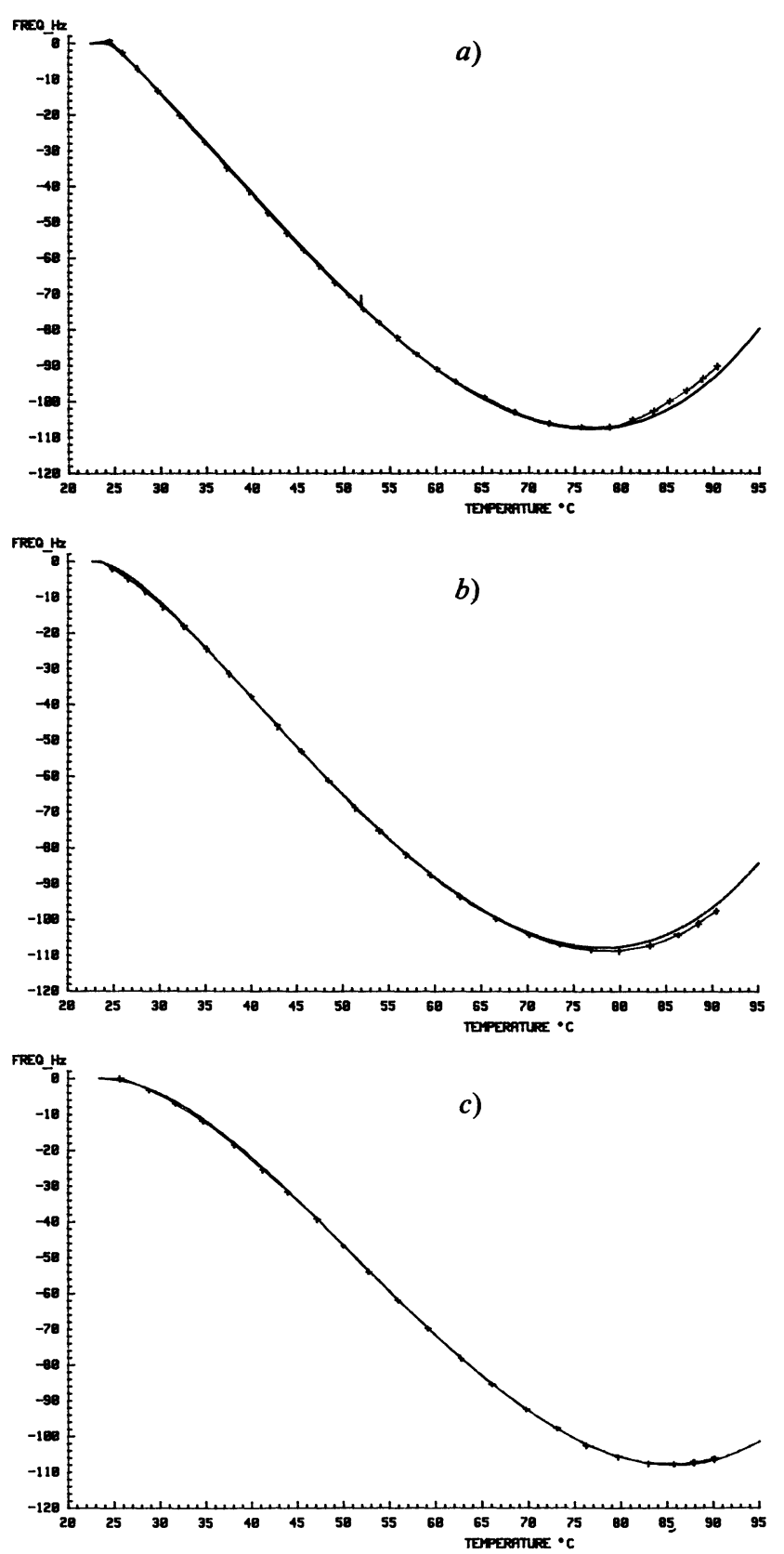

Fig. 8. - Frequency responses for ramp functions of temperature. a - Temperature increasing from $23^{\circ} \mathrm{C}$ to $95^{\circ}$ in 12 hours (quasi-static run), b - Temperature increasing in 3 hours, $\mathrm{c}-$ Temperature increasing in 1 hour.
It is difficult to distinguish, with such a frequency scale, the experimental and theorical curves : it is why crosses have been added on the experimental curves.

The curves of the figures $8 a-b-c$ show that the proposed theoritical interpretation allows to modelize as good manner the gap of frequency-temperature representations versus temperature variation speed.

This gap is particularly obvious at the turn-over points, i.e. $76^{\circ} \mathrm{C}$ in figure $8 \mathrm{a}$ and $86^{\circ} \mathrm{C}$ in figure $8 \mathrm{c}$.

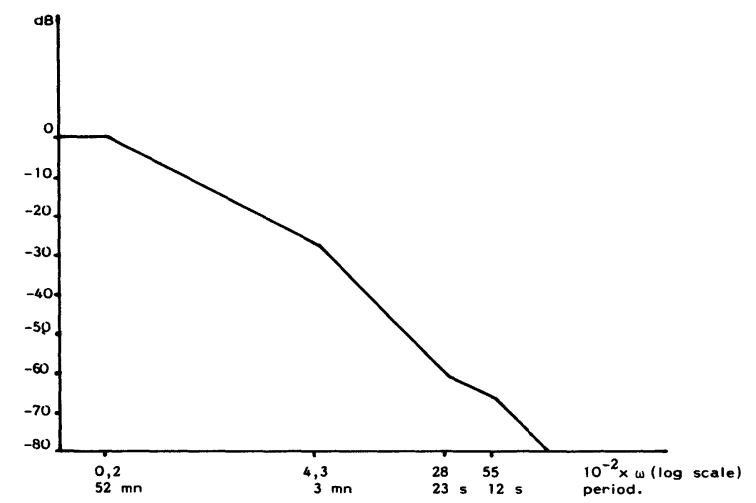

Fig. 9. - Bode diagram of a symmetrical structure B.V.A. resonator.

\section{Conclusion and future prospects.}

Of course, the studied resonator is not designed for fast warm-up, but analogical models may be used to study mounting structures adapted for that purpose. As shown figure 10, the frequency rise time when a resonator is subjected to a temperature step at the enclosure, depends upon the time constant of the structure : a « critical » state appears, which corrects the dynamic effect on the frequency. This possibility to remove transient effects by matching the crystal mounting structure must not be disregard.

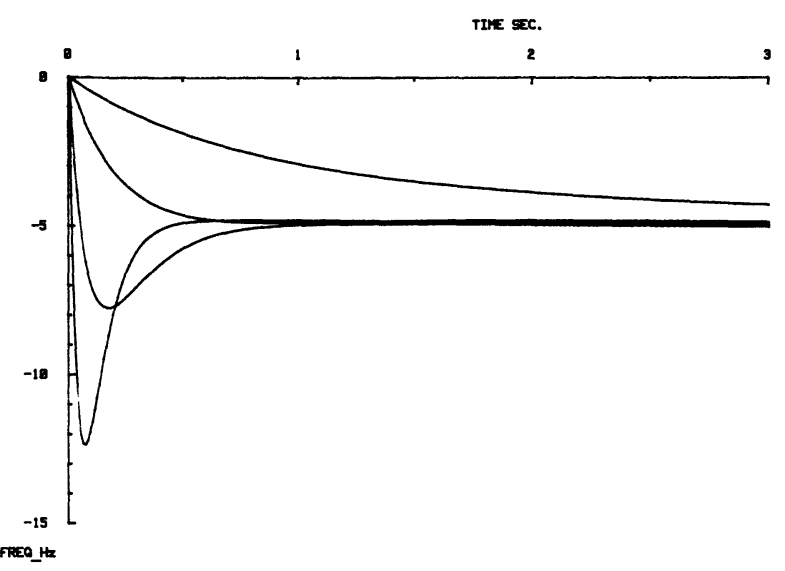

Fig. 10. - Effect of $2^{\circ} \mathrm{C}$ change. 


\section{Bibliographie}

[1] Galliou, S., Berthaut, A., Valentin, J. P., Nuovo Cimento 2 D, N 4 (1983) 1163.

[2] Valentin, J. P., J. Appl. Phys. 57, N² (1985) 492.

[3] Shockley, W., J. Acoust. Soc. Am. 41 (1967) 981.

[4] Valentin, J. P., Theobald, G., Gagnepain, J. J., J. Appl. Phys. (in press).

[5] Tiersten, H. F., J. Acoust. Soc. Am. 64, N 3 (1978) 832.

[6] Valentin, J. P., Ph. D. Thesis, $\mathrm{N}^{\circ} 178$, University of Besançon, France, 1983.

[7] Besson, R. J., Proceedings of the 31st Annual Frenquency Control Symposium (USAERADCOM, Ft. Monmouth, NJ), 147, 1977.

[8] Besson, R. J., Groslambert, J. M., Walls, F. L., Ferroelectrics 43 (1982) 57.
[9] Galliou, S., Ph. D. Thesis, $\mathrm{N}^{\circ} 2$, ENSMM of Besançon, France, 1982.

[10] Delaite, R., Revue Phys. Appl. (to be published).

[11] Janiaud, D., Ph. D. Thesis, $\mathrm{N}^{\circ} 78$, University of Besançon, France, 1978.

[12] CosARD, P., Techn. Ingénieur, B 90, p. 4-7, and Form. B 96, p. 10-16.

[13] General Electric, Heat transfer and fluid flow (Data books) Section 502.5, p. 3-23, 1970.

[14] Ballato, A. and VIG, J. R., Proceedings of the 32nd Annual Frequency Control Symposium (USAERADCOM, Ft. Monmouth, NJ), 180, 1978. 